\title{
The classic Theories of editing for the cinema and its impact on Video Games's narrative
}

\author{
Las Teorías clasicas del montaje cinematográfico \\ y su incidencia en la narrativas de los Videojuegos \\ Juan Pablo López Rincón \\ Universidad Nacional, Colombia
}

\begin{abstract}
Video games are an audiovisual form not necessarily narrative, however, day after day they have been improving in this facet (Gosciola 2009). They have their greatest strength, in the interactive relationship they share with their viewer, with his player, as (Pérez 2010) calls him. This author also mentions that video games allow to be co-creator of the text, and although there are other interactive audiovisual forms, video games occupy one of the most important places in this aspect. Still, as mentioned above video games have been evolving into the narrative aspect, for which they have resorted to taking elements from different places, one of them the cinema, elements that are important to identify. Therefore, the objective of this work was to identify these similarities in film editing, between film and video games. For this purpose, the concept of: Institutional Representation Mode (MRI) coined by Burch in 1970 was analyzed and a film was revised at the same time: (Intolerance.1916) of Griffith that exemplifies the conventions of the concept mentioned above, under the refuge of the conventions proposed by this concept, a comparison was made between the aforementioned film and two narrative video games of the last decade: (Heavy Rain. 2010) and (GTA V. 2013) this in order to point out in a timely manner the elements that have been brought from cinema to video games. After the analysis it was possible to show that video games apply the concept of MRI to their audiovisual narrative.
\end{abstract}

Keywords: Audiovisual Language, Film Editing, Video Games, Interactivity, Institutional Representation Mode.

\section{Introducción}

Los videojuegos se están posicionando como una industria cada día más fuerte en términos económicos según cifras de (Meristation 2020). No solo han avanzado como industria, sino que sus narrativas se hacen cada vez más complejas; por un lado, a partir de elementos de desarrollo de historias y, por el otro, con el desarrollo de un lenguaje audiovisual más sofisticado. En relación con esto último, el videojuego ha igualado como experiencia estética a otras artes representativas, entre ellas el cine como sostiene (Tavinor 2009) y aunque bastante se ha discutido si estos son considerados un arte o no, el debate sigue abierto, hay algunos como: (Tavinor 2009), (Jenkins 2009) e (Hidalgo 2011) quienes lo defienden como arte. Uno de los argumentos para definir los videojuegos como arte es:

\begin{abstract}
Comprendemos las reticencias que supone el reconocimiento oficial de una nueva forma dentro del campo de las artes, sobre todo de una con características tan innovadoras y poco convencionales como el videojuego, pero suponemos también que forma parte de un ciclo natural en los procesos de entendimiento y asimilación de lo nuevo. Basta recordar otras formas de arte, hoy muy posicionadas en su categoría artística, como la fotografía o el cine, las que sufrieron un proceso similar cuyo rechazo inicial fue absoluto para finalmente ser legitimadas como arte. (Hidalgo 2011, 102)
\end{abstract}

Es por esto que, de acuerdo a los postulados enunciados anteriormente, en este artículo se tomaran a los videojuegos como una pieza artística.

Retomando la idea de la experiencia estética, los videojuegos, al igual que el cine, utilizan elementos de otras formas artísticas como la pintura, la escultura, la música, la arquitectura, etc, lo cual, en términos de (Wagner 1849), los acerca a su concepto de "Arte Total" ${ }^{2}$. De igual manera, los videojuegos, ya desde su génesis, añaden el concepto de interactividad a toda esta ecuación de formas integradas, en la que el espectador pasa de ser un simple observador, para convertirse en protagonista del relato que está construyendo. En ese sentido, la narrativa de la obra necesita del público o jugador para ser llevada a cabo. Esta propiedad de los juegos de vídeo, sumada a los avances tecnológicos: visuales, gráficos y sonoros de los últimos años, los posiciona como una de las narrativas más complejas en la actualidad (Gosciola 2009). Para llegar a este nivel de complejidad estos han recurrido a traer estructuras, conceptos y elementos del cine.

Por otro lado, es importante agregar que los videojuegos además de ser objetos que sirven para el entretenimiento de niños, jóvenes y adultos, se han convertido en objetos de interés para el estudio por parte de distintas ramas del conocimiento como la pedagogía: (Etxeberria 2001), (Brown 2008), (Griffiths 2002); la psicología: (Villani, Carssoli, Triberti, Marchetti, Gilli y Riva 2018); las ciencias de la comunicación: (Peña y Hanckock 2006) entre otras, y de distintos académicos desde la perspectiva artística como por ejemplo: (Tavinor 2009), (Hidalgo 2011), entre otros. Aun así, hay temas, principalmente relacionados con el campo artístico, sobre los que se ha trabajado poco. El montaje cinematográfico aplicado a los videojuegos es una de esas áreas que parecen poco exploradas hasta la fecha puesto 
que a pesar de que de esta relación existen algunos estudios; estos no parecen ser lo suficientemente detallados y profundos para dar cuenta o describir cuáles son las formas cinematográficas presentes en este medio y de donde provienen.

En relación con lo expresado previamente, esta investigación tiene como objetivo identificar las similitudes en cuestiones de montaje cinematográfico entre el cine y los videojuegos, todo esto a través del análisis del término de: Modo de representación institucional acuñado por Noel Burch en dos de sus libros: Praxis del cine (1985) y El tragaluz infinito (1987). Y además con la ejemplificación a través del análisis comparativo entre una película que cumple con las convenciones propuestas en este concepto: (Intolerancia. 1916) de D.W. Griffith y dos videojuegos (Heavy Rain. 2010) y (GTA V .2013).

Finalmente, este texto está organizado en seis segmentos. En el primero se abordan los antecedentes de esta investigación, en el segundo el marco teórico desde donde se sustenta la investigación, en el tercero se presenta metodología a través de la cual se analizaron los materiales de la investigación. Luego de esto, se abordarán los resultados de la siguiente manera:

EL MODO DE REPRESENTACIÓN INSTITUCIONAL Y SUS CONVENCIONES EN LOS VIDEOJUEGOS: (HEAVY RAIN. 2010) Y (GTAV. 2013). En este apartado se analizan los videojuegos traídos a esta investigación, (Heavy Rain. 2010) y (GTA V. 2013) bajo la perspectiva del modo de representación institucional o MRI, concepto acuñado por Noel Burch en sus libros Praxis del cine (1985) y El tragaluz infinito (1987), para referirse a una serie de convenciones o normas que surgieron y se establecieron en la década de 1910 con el fin de organizar de manera coherente los relatos cinematográficos.

Luego en el siguiente apartado se encontrará: COMPARACIÓN ENTRE (INTOLERANCIA. 1916) DE GRIFFITH Y LOS VIDEOJUEGOS (HEAVY RAIN. 2010) Y (GTA V. 2010): ANALOGÍAS Y DIFERENCIAS ENTRE LOS DOS MEDIOS DE REPRESENTACIÓN.

En este se compara la película: (Intolerancia 1916) de Griffith con los videojuegos (HEAVY RAIN .2010) Y (GTA V. 2013) con el fin de encontrar las analogías y diferencias entre estos dos medios de representación bajo las convenciones establecidas por el MRI.

$Y$ por último se darán las conclusiones y consideraciones finales del trabajo.

\section{Desarrollo}

\section{ANTECEDENTES}

En torno al tema de la existencia de analogías entre los productos audiovisuales cinematográficos y los videojuegos. Son numerosos los autores que se han expresado al respecto. Entre ellos resulta importante resaltar a los siguientes: (Planells 2011) ha realizado trabajos en donde elabora una analogía estética entre las películas de la primera etapa del cine mudo o cine primitivo y los primeros videojuegos de las consolas arcades, a partir del concepto de Modo de Representación Primitivo (MRP), denominado así por Burch en 1968. En este análisis encontró similitudes entre el objeto de estudio planteado en relación a las convenciones establecidas por Burch para este concepto. De igual modo, investigadores como (Gosciola 2009) dan cuenta de aspectos comunes entre cine y videojuegos, y encuentran que el aspecto audiovisual en los videojuegos está tomando mayor relevancia en los últimos años, razón por la cual se les invierte más dinero y tiempo para su desarrollo. Por otro lado, (Salas 2016) encuentra que los videojuegos han tomado elementos del cine con el fin de satisfacer las necesidades de su público, el cual ya no se constituye solo de personas de corta edad, sino que se ha expandido a un público adulto que busca narrativas cada vez más complejas. Por último, (Videlva 2016) resalta que los videojuegos con énfasis en la narrativa suelen incorporar más elementos de otras formas artísticas como, por ejemplo, el cine.

\section{MARCO TEÓRICO}

Para el análisis se hace necesario apelar a alguno conceptos claves a definir como, por ejemplo: EL CINE Y EL MONTAJE CINEMATOGRÁFICO:

El cine, según señalan (Bordwell y Thompson 1995), es un arte que ofrece imágenes estáticas (fotogramas) a una cierta velocidad, que institucionalmente se estableció en 24 fotogramas por segundo. (Sánchez 1970) señala que el cine es una conjunción de movimientos indivisibles entre en el espacio y en el tiempo. En este sentido, (Tarkovski 2002) destaca la posibilidad de que el cine no solo le arrebata pedazos de tiempo y espacio a la realidad, sino que además lo amplía y enriquece al proyectar esa realidad de manera aumentada y amplificada en la pantalla cinematográfica.

Dentro del fenómeno del cine se encuentra quizá su elemento más importante, el montaje. El montaje cinematográfico, frecuentemente, como menciona (Sánchez 1970), suele confundirse con la etapa de la edición. Este mismo autor señala que el montaje es, por lo tanto:

un término estético que lejos de referirse a una etapa del proceso creativo, los abarca a todos por igual. De este modo, desde el momento en el que se comienza a concebir un film en la mente del cinematografista, y desde el momento en que él redacta un guion técnico en un papel que señala planos o tomas por separado, ya se está creando el montaje de ese film. (Sánchez 1970, 54)

En esa medida, para dar cumplimiento con el objetivo planteado en este análisis, se hace necesario apelar al concepto de Montaje de atracciones, un término empleado por el cineasta (Eisenstein 1949). De acuerdo con el autor, el montaje se define como el choque, la colisión de dos imágenes. De igual modo, define la toma cinematográfica como una célula, es decir, como la unidad más pequeña de una película. Esta célula cinematográfica se compone de lo que él denomina atracciones en las que se pueden incluir 
los elementos presentes en la puesta en escena y la puesta en cámara (la iluminación, la escala de los planos, la angulación, la escenografía, el color, el sonido, la música, etc.). Aunque en cada célula siempre existe una dominante que es la atracción más importante de esa célula, todas estas funcionan de manera independiente, pero siempre relacionadas con el conjunto en general, es decir, con el montaje.

Dentro del montaje cinematográfico existen ciertas convenciones que se han venido estableciendo a lo largo del tiempo, como por ejemplo el MRI (MODO DE REPRESENTACIÓN INSTITUCIONAL):

El término fue acuñado por Burch en dos de sus libros: Praxis del cine (1985) y El tragaluz infinito (1987), y alude a una serie de convenciones planteadas y utilizadas en el llamado periodo clásico del cine. Estas convenciones, aún vigentes y recogidas en el término MRI, fueron diseñadas por los cineastas entre 1910 y 1920, una época en la que se comienza a construir una forma artística como lo menciona (Gubern 2016).

De acuerdo con (Burch 1985), entre las convenciones que conforman el MRI se destacan las siguientes:

El fuera de campo: no limita la acción narrativa a lo que sucede en un único plano, sino que la acción se construye a través de la evocación de lo que no se ve en pantalla (el fuera de campo).

Raccord: relacionado con la convención anterior, ante la evocación del fuera de campo surge la necesidad de establecer unas normas para establecer continuidad espacial entre dos planos que no eran filmados de manera continua en la realidad. Alli surge el concepto de raccord ${ }^{2}$ que se puede aplicar a varios elementos fílmicos: la dirección de movimiento, la dirección de miradas, la continuidad de movimientos, la continuidad de los escenarios y la continuidad en la iluminación. Todo esto con el fin de lograr una transparencia narrativa, en la que el espectador no sea consciente del medio (el cine y sus artificios) mediante el cual se le está presentando la narrativa.

Elementos transicionales: estos elementos sirven para ordenar y dar una transición suave a la obra, destacan: fundido a negro y encadenado.

Montaje paralelo: se refiere a la sucesión de dos acciones que suceden al mismo tiempo, pero no en el mismo espacio.

Montaje alternado: se refiere a el montaje sucesivo de distintas escenas que ocurren en tiempos y espacios diferentes.

Planificación visual jerárquica: se refiere en un orden de la aparición de los planos que va de la siguiente manera: planos abiertos, planos medios y planos cerrados. Todo esto acorde con la progresión dramática de la escena.

Composición y fragmentación del espacio: se refiere a recurrir a una diversa variedad de planos y angulaciones; además, como señala (Sánchez 1970) realizar la composición de la imagen según la "regla de los tercios" la cual evita que el personaje se ubique en el centro del cuadro, y busca ubicarlo en uno de los llamados puntos fuertes.
Efectos plásticos y fotográficos: se refiere a utilizar los efectos fotográficos y plásticos ofrecidos por la imagen para generar sensaciones en el espectador. ${ }^{3}$

Intertítulos: consiste en la utilización de texto para explicar, exponer o señalar situaciones en las películas mudas.

Además, como concepto clave del análisis encontramos el concepto de VIDEOJUEGO el cual posee una gran complejidad a la hora de intentar definirse. (Wolf y Perron 2005) consideran que los videojuegos poseen los siguientes elementos fundamentales: algoritmo, actividad del jugador, interfaz y gráficos; por su parte (Juul 2005) lo entiende desde un enfoque ludológico e indica que los videojuegos traen las estructuras de los juegos tradicionales y las adaptan a un entorno computacional. Como lo menciona (Hidalgo 2011), dentro del campo académico no se tiene una sola definición que abarque la complejidad de este nuevo medio artístico. Por lo anterior, la autora propone diseñar una definición a partir del establecimiento de un conjunto de condiciones que pueden no ser totalmente indispensables, pero que al ser combinadas son capaces de proporcionar una definición. Así, para definir este concepto se hace necesario aludir a tres elementos centrales: lo narrativo, lo audiovisual y lo interactivo.

Lo narrativo: según (Tavinor 2009) se encuentra una corriente de análisis de los videojuegos conocida como la corriente narratológica, la cual propone que los videojuegos son textos capaces de contar historias, es decir, se caracterizan como nuevas formas narrativas que se pueden estudiar a partir de estructuras ya existentes como: la novela y el cine, por ejemplo. No obstante, como asegura (Hidalgo 2011), aunque existen videojuegos que en una primera instancia parecen no poseer una narrativa como (Tetris. 1984), por ejemplo; si se analizan más a profundidad, estos poseen la noción de éxito y de fracaso, lo cual los acerca en cierta forma a una narrativa, aunque sea de manera simple.

Lo audiovisual: (Gosciola 2009) considera que los videojuegos utilizan imágenes y sonidos para exponer las historias al jugador y los concibe como un medio de comunicación audiovisual. Sobre este aspecto cabe añadir que, como lo menciona (Hidalgo 2011), el videojuego es un medio audiovisual digital, ya que su concepción y nacimiento se da precisamente en el inicio de la era digital. Esto es especialmente importante para diferenciarlo de otra clase de propuestas lúdicas, y además bajo esta característica de ser un medio digital necesita de una interfaz (sea consola $u$ ordenador, etc.) para poder ser llevado desde el lenguaje de programación hasta el espectador. A pesar de que (Hidalgo 2011) añade la necesidad de un recuadro o pantalla en la cual el videojuego se desarrolla, esto se puede refutar fácilmente en la actualidad con la aparición de dispositivos de realidad virtual. Estos permiten al videojuego liberarse del recuadro o la pantalla, razón 
por la cual, en la actualidad conviven dos modalidades: aquellos videojuegos que requieren necesariamente una pantalla y los que pueden prescindir de ella.

Lo interactivo: autores como (Pérez 2010) definen al jugador de un videojuego no como un receptor, sino como un usuario implícito que se puede entender como un receptor implícito, que se remite a las narrativas clásicas en la cual el jugador es un producto de la composición del texto, es decir, se limita a seguir una narrativa establecida. Por otro lado, se encuentra el receptor/usuario implícito, el cual no es producto del texto, sino que más bien cocreador del mismo, es decir, a partir de sus decisiones la narrativa avanza por uno u otro camino, estas decisiones se pueden tomar a partir de distintos tipos de interacción con la interfaz del videojuego, estas pueden ser como mencionan (Prieto, Medina y Lopez 2016) una interacción estándar, activa o pervasiva.

A partir de la definición de estas características, un videojuego se define como: un medio audiovisual digital que utiliza las imágenes y los sonidos para exponer o comunicar una narrativa sea esta sencilla o compleja para un jugador. Este último puede ser definido como producto del texto o como cocreador del mismo y participa en la obra a través de una interfaz (consola, ordenador, entre otros y sus distintos tipos de controles) que puede estar enmarcada en un recuadro (pantalla) o no (realidad virtual).

En la mayoría de videojuegos existen dos momentos: el gameplay ${ }^{4}$ y las cutscenes ${ }^{5}$.

El gameplay: como lo define (Santoyo 2013) es el momento que se da cuando el jugador puede controlar a su personaje e interactuar con el mundo propuesto con el videojuego, y comprobar que es posible hacer y qué no dentro del universo jugable.

Las cutscenes: como lo define (Jimenez 2018) un fragmento de vídeo que se activa en ciertos momentos específicos del videojuego y que tiene una característica cinematográfica.

A partir de estos conceptos se sustentó el análisis de los objetos de estudio.

\section{MARCO METODOLÓGICO}

\section{CARACTERÍSTICAS DE LOS MATERIALES} A ANALIZAR: La película escogida para realizar el análisis es Intolerancia, un filme silente que tiene una duración de tres horas treinta minutos aproximadamente, y fue realizado en 1916 por el director estadounidense D.W Griffith. Esta obra cuenta cuatro historias inconexas temporalmente, pero que tienen como tema central, la intolerancia del ser humano a sus semejantes a través de la historia. A pesar de lo compleja que pudo ser la trama de la película para la época en que fue realizada, el filme utiliza los recursos del montaje cinematográfico para exponer la narrativa de la manera más clara posible, hay que tener en cuenta que el cine en esta época era un producto y un lenguaje nuevo por lo cual los espectadores no estaban lo suficientemente acostumbrados a este, y era necesario ser muy preciso con la manera de contar la historia no solo desde la trama, sino también desde los recursos audiovisuales para que no existiera confusión en el espectador, para lo cual se comenzó la búsqueda de un lenguaje y unas convenciones que hicieran posible la legibilidad de las películas para cualquier tipo de público, y en esa búsqueda esta película es una de las pioneras.

Los videojuegos seleccionados para el análisis son: Heavy Rain desarrollado en 2010 por la compañía Quantic Dream y diseñado por David Cage, y Grand Theft Auto V (GTA) desarrollado en 2013 por Rockstar North y Rockstar Games, y diseñado por Leslie Benzies y Imran Sarwar.

El primero, (Heavy Rain. 2010) es un videojuego de género thriller-drama que cuenta la historia de Ethan, un hombre que busca rescatar a su hijo de un asesino que se hace llamar el asesino del origami. En el videojuego es posible controlar hasta cuatro personajes, aun así, el videojuego impone en qué momento es posible controlar a cada uno. Este videojuego como apunta (Cuadrado 2013) busca dirigirse a la emoción del espectador, en este el jugador decide el rumbo de las distintas situaciones que se le van presentando a través de su elección de las opciones que el juego le coloca en pantalla a través de distintos botones o teclas. A pesar de eso el videojuego está limitado a este modo historia, es decir el jugador si o si debe avanzar en la trama. Por lo cual el gameplay y las cutscenes van de la mano, haciendo que no se sienta un cambio abrupto entre las escenas en las que el jugador posee el control del personaje y en las que no.

El segundo, (GTA V. 2013) es un videojuego de mundo abierto, es decir el jugador puede explorar libremente todo el mapa a su antojo sin tener que obligatoriamente avanzar en el modo historia si este no lo desea. El videojuego se enmarca en el género acción-aventura, en el que se sigue la historia de tres protagonistas: Michael, Trevor y Franklin a través de distintas misiones y atracos para hacerse con el control de la ciudad ficticia de Los Santos. Así mismo, el jugador tiene la libertad luego de completar las misiones iniciales de controlar al personaje que quiera en el momento que desee, sin limitaciones. Para que el jugador avance con la historia debe completar distintas misiones que le son señaladas en el mapa del juego con distintos iconos. En este videojuego se siente una gran diferencia entre las cutscenes y el gameplay, ya que las cutscenes son momentos en los que el jugador no puede hacer nada más que observar, esta diferencia se produce gracias a que como se mencionó el videojuego no obliga al jugador a completar el modo historia para jugar, sino que el jugador decide en qué momentos desea realizar misiones y en qué momentos desea hacer exploración libre del universo jugable.

CRITERIOS DE SELECCIÓN Y JUSTIFICACIÓN DE LA MUESTRA: En relación con la película, se incluyó esta muestra atendiendo a cuatro criterios:

Marco temporal de la producción: la película debe haber sido realizada entre los años 1910 y 1920 , retomando las ideas de Gubern (1969), en esta época 
el cine comenzó a organizarse alrededor de unas convenciones que permitieron crear un lenguaje que al ser transmitido fuera coherente para el espectador en diversos apartados.

Cumplimiento de la convención de Modo de Representación Institucional: el cumplimiento de estas convenciones asegura que el espacio fílmico tenga coherencia y transparencia narrativa.

Importancia para su época: en términos de lenguaje cinematográfico un antes y un después de su creación.

Influencia sobre el cine en la actualidad: mantenerse vigente en cuestiones de lenguaje cinematográfico a pesar de su longevidad.

Es bajo estos criterios que se ha seleccionado la película: Intolerancia dirigida por D.W Griffith que como lo menciona (Marzal 2015) ha sido una película que ha influenciado tanto al cine de su época como al cine realizado aún hoy en día más de cien años después. Asimismo, menciona que su director D.W Griffith es considerado el padre del cine como lo conocemos actualmente.

Para la selección de los videojuegos, los criterios más relevantes son:

Marco temporal de producción: los videojuegos deben situar su desarrollo en la década que comprende desde el año 2010 hasta el año 2020, esto debido a que en esta época se sitúan los videojuegos más recientes a la fecha de realización de este artículo. Además de esto, (Hidalgo 2011) menciona que a partir del año 2000 los videojuegos comenzaron a utilizar el sistema de 128 bits que ayuda en cuestiones técnicas a la generación de gráficos cada vez más cercanos a la realidad

Presencia de gráficos 3D: los videojuegos deben tener físicamente una representación que se ajuste al término de hiperrealismo como lo entiende (Hidalgo 2011). El autor lo define a través del tratamiento que se les da a los ambientes, las texturas, las luces $\mathrm{y}$, en general, todo lo que compone la atmósfera del videojuego.

Proyección del usuario: estos videojuegos deben proyectar al usuario a través de una pantalla. Para el análisis comparativo, un juego en realidad virtual, por ejemplo, no sería de utilidad bajo las convenciones establecidas por el MRI al prescindir del elemento del recuadro (pantalla) que es el que este conjunto de convenciones se encarga de organizar.

Jugabilidad: los videojuegos deben tener la posibilidad de que el jugador controle a más de un personaje.

Función del jugador: en términos narrativos, los videojuegos seleccionados deben ofrecer la posibilidad al jugador o, como lo denomina (Pérez 2010), al usuario, de ser cocreador de la narrativa del videojuego a partir de las decisiones que este tome.

Procedimientos para el análisis del material:
1. A través de las nueve convenciones mencionadas bajo el concepto de MRI se realizó un cuadro comparativo en el que a través del análisis del gameplay y las cutscenes de los videojuegos seleccionados, se determinó si estos cumplían o no con cada una de las distintas convenciones estilísticas establecidas.

2. Luego de determinar la aparición o no de las convenciones establecidas, se procedió a realizar un análisis detallado, convención por convención para comprobar de qué manera los dos videojuegos establecidos como muestra interpretan la convención y la llevan a su respectiva narrativa.

3. Por último y a través del análisis comparativo entre la película y los videojuegos, se pueden encontrar las diferencias y transformaciones que sufre la convención al ser adaptada a un medio distinto (del cine a los videojuegos) de esta manera encontrando las analogías estéticas entre uno y otro medio.

\section{RESULTADOS}

\section{EL MODO DE REPRESENTACIÓN INSTITUCIONAL Y SUS CONVENCIONES EN LOS VIDEOJUEGOS (HEAVY RAIN. 2010) $Y$ (GTA V. 2013).}

Con el fin de cumplir con el objetivo de encontrar similitudes entre el cine y los videojuegos se recurrió primero que todo a un análisis general, en el cual, a través del análisis del gameplay de los videojuegos seleccionados y bajo la mirada de las convenciones del MRI enunciadas anteriormente, se extrajeron los resultados evidenciados en la siguiente tabla:

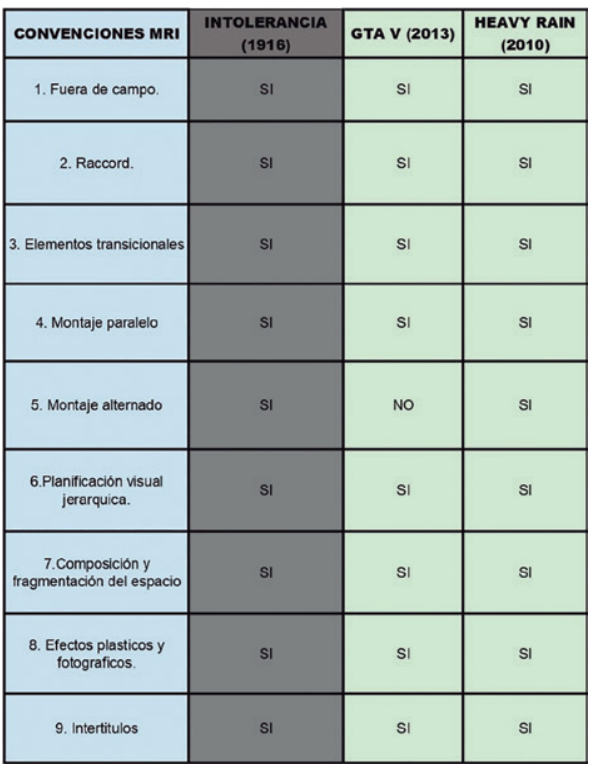

Figura 1 - Tabla de convenciones. Producción propia. 
En el análisis general, fue posible encontrar presentes de una $\mathrm{u}$ otra forma las convenciones establecidas por el: Modo de representación institucional, en (Heavy Rain. 2010) se encontraron todas las normas señaladas y en (GTA V. 2013) se pudieron evidenciar todas excepto una, la número 5 que se refiere al montaje alternado.

Una vez establecido un panorama general respecto a los materiales a analizar, fue importante analizar estos fenómenos más a fondo para encontrar de qué manera fue posible hallar estas convenciones en un medio distinto al cinematográfico, cabe aclarar que las formas encontradas no siempre serán cien por ciento fieles a lo expresado desde el campo cinematográfico, y la segunda parte del análisis de resultados se encargará de subrayar esas diferencias.

Para dar paso a un análisis cualitativo de los resultados se utilizó el mismo orden de las convenciones dado en la tabla y en el marco teórico.

\section{Fuera de campo}

Heavy Rain: Esta convención no es difícil de localizar, ya que el hecho de fragmentar el espacio en distintos tipos de planos, provoca que exista siempre un fuera de campo, al romper con la autarquía que dicta que todo lo necesario para comprender la acción de encuentra en el mismo cuadro. Este elemento ayuda a potenciar las escenas de suspenso presentes en el videojuego como se puede observar en la figura 2 , en el que además se conjugan otros elementos que no es posible percibir en los fotogramas mostrados, pero que están presentes como: los efectos sonoros y la música. En esta escena del videojuego una presencia perturba a la periodista Madison, alguien la acecha en su apartamento, pero ella no sabe qué es, esto produce una tensión alrededor de lo que no se puede ver, lo que no es mostrado, el fuera de campo, pero que se enuncia a través de los ruidos extraños que ella percibe en su apartamento. Este elemento se hace presente tanto en las cutscenes como en el gameplay, y no siempre cumple la función de generar suspense, ya que como se ha explicado anteriormente el solo hecho de fragmentar un espacio en distintos tipos de planos, naturalmente ya produce un fuera de campo.

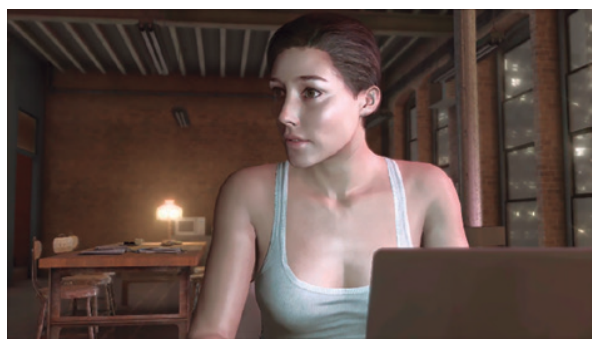

Figura 2 - Fuera de campo en Heavy Rain. Tomado de: https:// bit.ly/33rgbxB
GTA V : La posición de cámara desde la cual el jugador accede al gameplay en este videojuego, favorece la enunciación del fuera de campo, la cámara permanece como se observa en la figura 3, en tercera persona con ángulo ligeramente picado y un ángulo de visión limitado, es el jugador el que frecuentemente tiene el poder de controlar la dirección hacia donde apunta la cámara, esto genera frecuentemente, pero sobre todo en las escenas de disparos un campo y un fuera de campo que el jugador puede gestionar moviendo la cámara hacia un lado o hacia otro, convirtiendo el fuera de campo, en el campo y viceversa, con esto haciendo efectiva la posibilidad interactiva del videojuego, en la que el jugador puede decidir sobre varios aspectos del mismo. Acá al igual que en (Heavy Rain. 2010) el sonido es importante para de cierta manera guiar la atención del jugador hacia uno u otro punto, como por ejemplo el sonido de las sirenas de policía o los disparos, a pesar de la libertad de movimiento con la que esta cuenta.

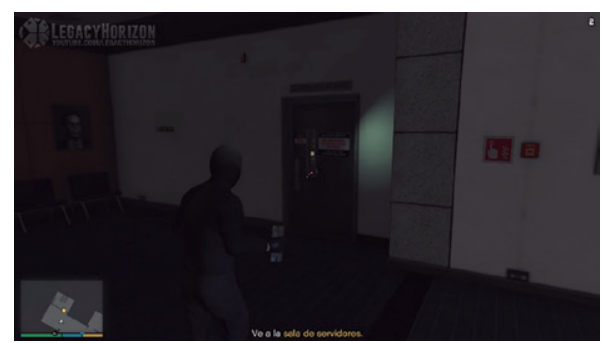

Figura 3 - Fuera de campo en GTA V. Tomado de: https://bit. Iy/2QXHME3

\section{Raccord}

Como se mencionó en el marco teórico el raccord se refiere a la continuidad, esta continuidad se da en varios elementos como: la dirección de movimiento, la dirección de miradas, la continuidad de movimientos, la continuidad de los escenarios y la continuidad en la iluminación. En (Heavy Rain. 2010) y (GTA V. 2013) se cumplen todos estos principios enunciados con el fin de garantizar la transparencia narrativa y un espacio coherente, este elemento es especialmente utilizado en las cutscenes, aun así, el principio de continuidad lumínica y continuidad de escenarios está presente también en el gameplay. En cuanto a elementos como la dirección de movimiento, la dirección de miradas y la continuidad de movimientos, cabe establecer una diferencia entre los dos videojuegos analizados. En Heavy rain el jugador no puede modificar la posición de la cámara a voluntad, sino que la posición de la cámara se va modificando según la ubicación del personaje en el espacio, es decir la cámara no sigue al personaje. Esto lleva a que entre las distintas posiciones de cámara establecidas a medida que se avanza en el espacio debe existir continuidad de dirección conforme el jugador desplaza al personaje por el espacio para que el jugador pueda percibir un espacio coherente. Mientras tanto en GTA $V$ como 
se mencionó en el primer punto el jugador tiene la posibilidad de manejar la cámara a placer, aunque claramente existe la limitación de que puede variar la dirección y el ángulo, pero siempre alrededor del personaje, esto hace que realmente la continuidad de la dirección de movimiento y la dirección de miradas la establezca el mismo jugador.

\section{Elementos Transicionales}

En los dos videojuegos se presentan elementos de transición básicos como son el fundido a negro, o transiciones por medio de barridos, sin embargo, otros como el cierre del iris (se evidenciará en el siguiente apartado) no es posible encontrarlo en ninguno de los dos videojuegos. En GTA $V$ se puede encontrar un elemento de transición que se puede observar en la figura 4. Se utiliza un time-lapse para hacer la transición entre un punto temporal y otro en una misión de manera rápida y ágil.

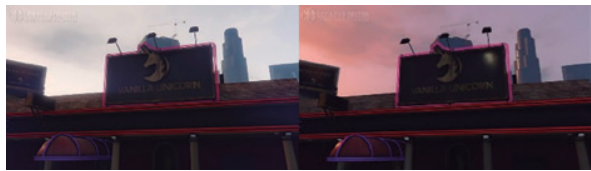

Figura 4 - Timelapse en GTA V. Tomado de: https://bit. ly/3bfOn $3 n$

\section{Montaje paralelo}

Heavy Rain: En este videojuego es posible encontrar una manera interesante de llevar a la pantalla uno de los recursos más importantes del MRI. (Heavy Rain. 2010) recurre a una división interna del cuadro, en la cual se utilizan otros recuadros más pequeños para mostrar distintas situaciones que ocurren al mismo tiempo, como se puede apreciar en la figura 5. De esta manera se puede conseguir suspense y tensión en el espectador, la escena mostrada en este fotograma corresponde a la muerte del hijo de Ethan que sucede al comienzo del videojuego y la desesperación de su padre por evitar que lo atropelle el coche.

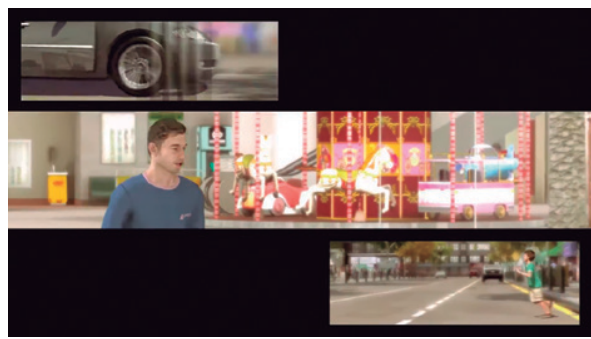

Figura 5 - Montaje parelo en Heavy Rain. Tomado de: https:// bit.ly/33wwPM6

GTA V: Por otro lado, en (GTA V. 2013) este recurso es vital en el desarrollo de ciertas misiones en la que es necesaria la cooperación de los tres personajes con los cuales el jugador puede interactuar. Dentro de las misiones y fuera de estas el jugador puede cambiar ágilmente de personaje como se puede observar en la figura 6, generando un efecto similar al conseguido con el montaje paralelo mencionado por el MRI. Como se mencionó antes este recurso es muy importante para varias misiones del juego, así que este recurso se incrusta directamente en la narrativa del videojuego de una manera clave. Además, este recurso está disponible para que el jugador pueda utilizarlo aún fuera de las misiones establecidas por el juego, de esta manera puede saltar entre los distintos personajes y encontrar a estos realizando distintos actos cotidianos de sus vidas dentro del videojuego.

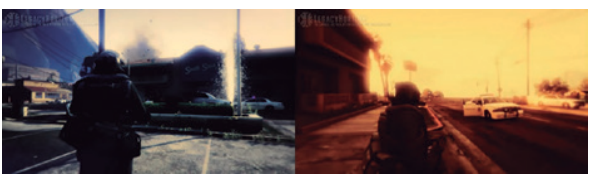

Figura 6 - Montaje paralelo en GTA V. Tomado de: https://bit. ly/3bfOn3n

\section{Montaje alternado}

Este recurso es posible encontrarlo en el videojuego (Heavy Rain. 2010) a través del cambio de personajes que va haciendo avanzar la narrativa del videojuego, se diferencia del montaje paralelo ya que este no se produce entre acciones que ocurren en el mismo tiempo, sino en tiempos y espacios distintos, la narrativa de este videojuego se va desarrollando entre personajes que en un comienzo no tienen ninguna relación, pero que, conforme se va utilizando este recurso y el jugador va tomando decisiones importantes para el desarrollo de la trama, estas historias mostradas a partir de un montaje alterno se van entrelazando las unas con las otras construyendo de esa manera la narrativa de este videojuego.

\section{Planificación visual jerárquica}

Esta convención se puede evidenciar en los dos videojuegos principalmente en las cutscenes, que están planteadas a partir de primero un plano general con el fin de que el espectador establezca un mapeado del espacio, sus dimensiones y direcciones e ir progresivamente cambiando hacia planos más cerrados, pero manteniendo las direcciones establecidas en el plano de establecimiento o plano general.

\section{Composición y fragmentación del espacio}

Heavy Rain: el gameplay en (Heavy Rain. 2010) como se ha mencionado anteriormente está organizado de manera en la que la cámara no se posiciona detrás del personaje si no que esta está predeterminada de acuerdo a la localización del personaje en el espacio, por lo cual la magnitud y las angulaciones de cámara son mayores, esto genera una mayor fragmentación del espacio. Además de esto, el recurso de dividir la 
pantalla para mostrar distintos ángulos de cámara también es una manera novedosa de fragmentar el espacio como se puede observar en la figura 7, en la que se puede observar cómo conviven dos tamaños de plano distintos dentro de él mismo cuadro, un primer plano del rostro de la mujer, y un plano general del investigador privado Scott de espaldas a cámara. En otros momentos del videojuego es posible evidenciar el mismo recurso como se puede ver en el punto sobre el montaje paralelo.

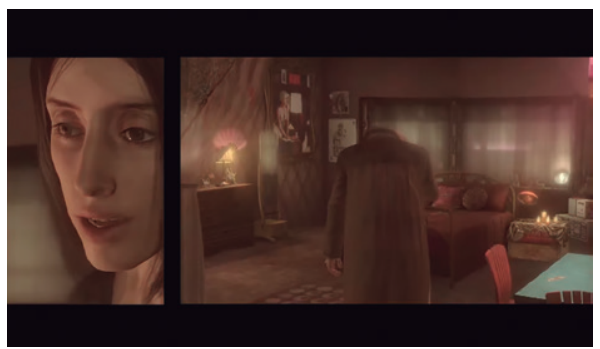

Figura 7- Fragmentación del espacio en Heavy Rain. Tomado de: https://bit.ly/3odeHRf

GTA V: la fragmentación del espacio en este videojuego está más dada desde las cutscenes, sin embargo, como se ha mencionado anteriormente el jugador puede controlar la cámara con cierta libertad, lo cual permite que varíe las magnitudes de los planos y sobre todo las angulaciones, sin embargo, esto no se produce por "corte directo" sino recuerda más a un plano secuencia con movimiento de cámara. por "corte directo" encontramos que el jugador a través de ciertas teclas o botones puede modificar la magnitud del plano cuando va conduciendo un vehículo a distintos tipos y angulaciones de cámara.

\section{Efectos plásticos y fotográficos}

Heavy Rain: en este videojuego se recurre a efectos fotográficos tanto para justificar puntos de vista como se puede evidenciar en la figura 7, como para resaltar los estados psicológicos de sus personajes a lo largo del juego. En la figura 8 se está observando al personaje de Scott a través del ojo de una puerta, y se recurre al efecto fotográfico para que esta intención sea clara y coherente.

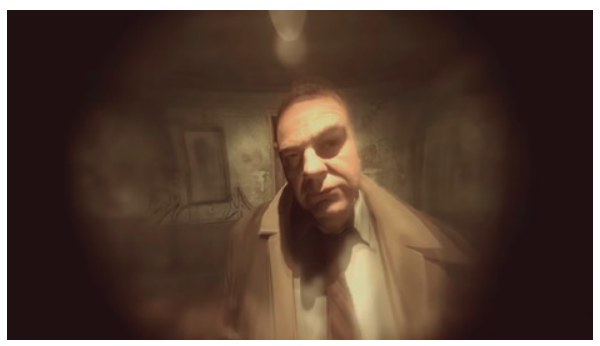

Figura 8- Efecto fotografico en Heavy Rain. Tomado de: https://bit.ly/3odeHRf
GTA V: en este videojuego se utiliza distintos efectos fotográficos para resaltar las habilidades especiales de los personajes, cuando estas habilidades están activas la pantalla toma un tinte de un color distinto dependiendo del personaje que se esté controlando: en el caso de Trevor, el recuadro toma un tinte naranja, en el caso de Franklin, un tinte verde y en el caso de Michael, un tinte azul, esto va acompañado de un desenfoque y una luz difuminada. Todo esto con miras a que el jugador pueda diferenciar cada una de las habilidades especiales de los personajes y aprovecharlas en el videojuego.

\section{Intertítulos}

El texto escrito o intertítulos también se hacen presentes en los diferentes textos informativos e instructivos en los dos videojuegos como se puede observar en la figura 9, sin embargo, en (Heavy Rain. 2010) estos textos cumplen también una función clave dentro del gameplay, ya que gracias a estos textos el jugador conoce las distintas opciones entre las que puede elegir para hacer avanzar la trama como se puede observar en la figura 10.

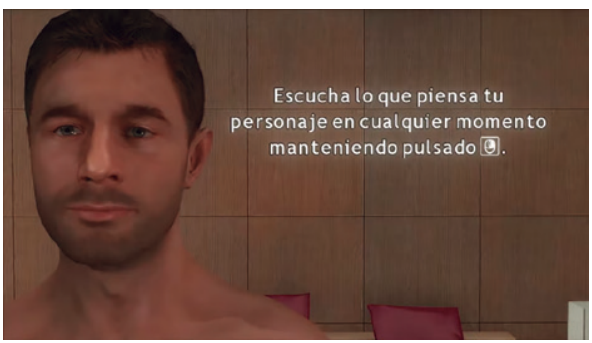

Figura 9 - Texto instructivo en Heavy Rain. Tomado de: https:// bit.ly/33wwPM6

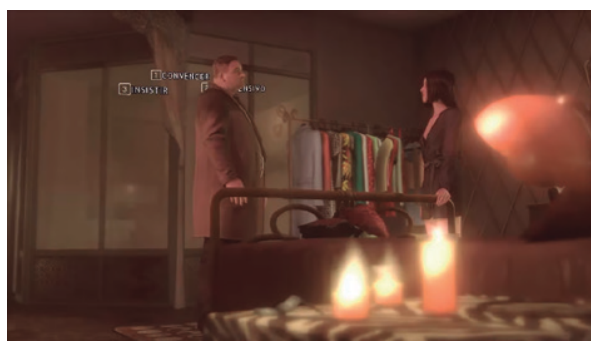

Figura 10- Texto de selección para decidir que acción realiza el personaje. Tomado de: https://bit.ly/3odeHRf

\section{COMPARACIÓN ENTRE (INTOLERANCIA. 1916) DE GRIFFITH Y LOS VIDEOJUEGOS (HEAVY RAIN. 2010) Y (GTA V. 2010): ANALOGÍAS Y DIFERENCIAS ENTRE LOS DOS MEDIOS DE REPRESENTACIÓN.}

Luego del análisis detallado adelantado en el apartado anterior, fue posible traer a colación el otro material al cual recurre esta investigación y es la película (Intolerancia. 1916) dirigida por D.W 
Griffith. Esta película como se mencionó en el marco metodológico cumple con las condiciones establecidas por el MRI. Por tanto, el análisis de esta se centró solamente en los elementos que puedan ser realmente llamativos para los resultados de la investigación.

En primer lugar, vale la pena resaltar el montaje paralelo y el montaje alterno, que son elementos centrales en la película de Griffith, y que como se pudo evidenciar en el análisis del apartado anterior también aparecen enunciados en los dos videojuegos analizados: (Heavy Rain. 2010) y (GTA V. 2013), sin embargo, cabe indagar qué diferencias es posible encontrar en la utilización de estos dos recursos en dos medios distintos: el cine y los videojuegos. Por un lado, en Heavy Rain se puede evidenciar una utilización similar a la propuesta por (Intolerancia. 1916) a pesar de que plásticamente pueda diferir un poco, el montaje paralelo es utilizado para generar emoción y tensión en el filme al igual que en el videojuego, a pesar de que en el videojuego se utilice el recurso de dividir el recuadro para hacer uso del montaje paralelo, el objetivo es el mismo que en la película. En el caso del montaje alterno, también guardan una similitud muy grande dado que este tipo de montaje cumple la misma función en las dos narrativas, presentar la perspectiva de otro personaje en otro tiempo y otro espacio. Sin embargo, cuando se compara la utilización del montaje paralelo que hace el filme con la que hace el videojuego (GTA V. 2013) es posible encontrar varios puntos de divergencia pero que hacen interesante el análisis. Primeramente, para este recurso es necesario retomar el concepto de interactividad definido desde los postulados de (Pérez 2010) desde los cuales el jugador es un usuario implícito que no se limita solo a recepcionar información sino que es capaz de coescribir el texto, en GTA V el jugador puede realizar este montaje paralelo a voluntad cuando está en modo de exploración libre, y aunque el juego impone limitaciones durante las misiones, el jugador sigue teniendo la facultad de saltar entre los tres personajes a su antojo lo cual genera una diferencia notable con el recurso mencionado en la película, en la cual el espectador se limita simplemente a ser llevado por la emoción y la tensión en un ritmo propuesto por el realizador o director de la película. Este mismo recurso se acerca al concepto de choque utilizado por Eisenstein (1949) para definir el montaje, ya que ese choque entre células o planos (cambio de un personaje a otro) genera también que el espectador, en este caso jugador, tenga que estar alerta para poder adaptarse a ese choque de espacios $y$ de perspectivas que propone el montaje paralelo en este videojuego.

Existen otros dos elementos o convenciones que son muy interesantes de analizar en relación a su utilización entre estos dos medios audiovisuales. Por un lado, están los efectos fotográficos, y por el otro los intertítulos. Estos dos elementos son muy similares en cuanto a la función que cumplen dentro de las narrativas tanto en el filme (Intolerancia. 1916) como en los videojuegos (Heavy Rain. 2010) y (GTA V. 2013)
En la película, los efectos plásticos y fotográficos rompen con la transparencia que busca tener el relato, es decir que estos efectos se subrayan dentro del filme, esto se puede notar en la figura 11 y 12.

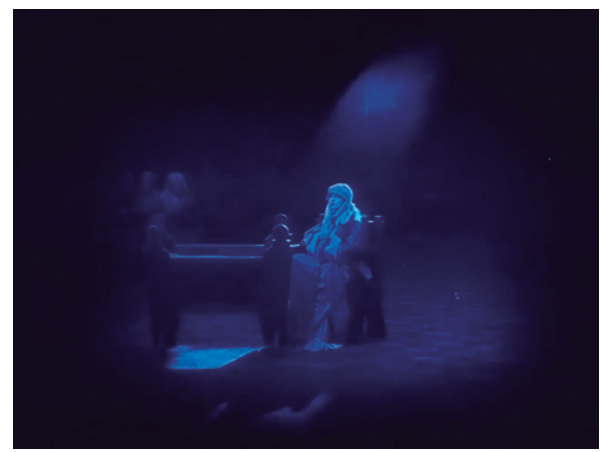

Figura 11- Efecto fotografico en Intolerancia. Tomado de: (Intolerancia. 1916)

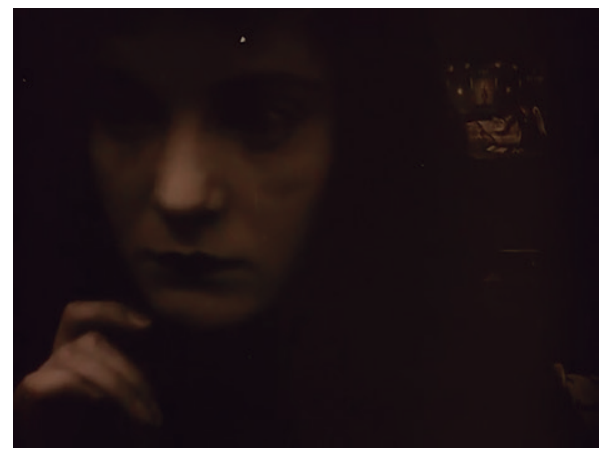

Figura 12- Efecto fotografico en Intolerancia. Tomado de: (Intolerancia. 1916)

En los videojuegos, en esos efectos plásticos y fotográficos se manifiestan de unas maneras muy similares, con una función muy parecida y subrayándose también en el relato, como, por ejemplo, las habilidades especiales en el videojuego GTA $\vee$ y como estas se representan a través de efectos fotográficos con el fin de que el jugador pueda reconocer si la habilidad de ese personaje está activa y en qué nivel está incidiendo en la jugabilidad.

Por último, es importante destacar la utilización de intertítulos dentro de la película, que son claves para exponer al espectador la trama y hacer que este la comprenda, ante la ausencia del sonido como se observa en la figura 13. 


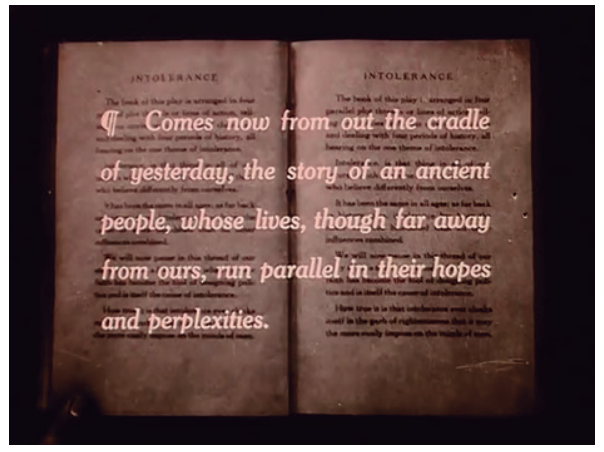

Figura 13- Intertitulos en intolerancia. Tomado de: (Intolerancia. 1916)

Este elemento es clave para la narrativa y la jugabilidad de los videojuegos, a pesar de que estos si cuentan con el elemento sonoro. Esto gracias a que los intertítulos ofrecen en los videojuegos al igual que en el cine, una manera didáctica y fácil de comprender a la hora de comunicar información importante para el videojuego. Esto como se puede observar en los ejemplos dados en la primera parte del análisis de resultados, es un elemento clave a destacar como una analogía entre los dos medios, sobre todo basados en el análisis de una película muda.

\section{Conclusión}

A partir de este artículo se ha intentado primero que todo dar una definición lo más precisa posible por medio del enfoque narrativo, audiovisual e interactivo del término videojuego. $Y$ buscar a partir de las estructuras utilizadas en estudios cinematográficos encontrar estructuras que puedan aplicarse para el estudio de los videojuegos, siendo que a pesar de que los videojuegos tienen casi cincuenta años desde su creación, hasta hace relativamente poco ha comenzado a estudiarse de manera dedicada (game studies). Una vez definido el término se ha buscado encontrar una estructura traída del lenguaje cinematográfico, como es el: Modo de representación institucional acuñado por Burch en 1970. A través de una serie de convenciones reunidas en este término y de la comparación entre dos videojuegos: (Heavy Rain. 2010) y (GTA V. 2013) con la película (Intolerancia. 1916) del análisis se pudo obtener que la mayoría de convenciones establecidas por el MRI se pueden evidenciar en el análisis de los videojuegos, de manera que allí ya se encuentra presente la raíz cinematográfica que ha sido importante para la gran evolución que han venido teniendo los videojuegos en los últimos años en los distintos campos analizados para la definición: lo narrativo, lo audiovisual y lo interactivo.

Un elemento destaca en particular de lo encontrado en el análisis, y es la aparición en los videojuegos de la noción de montaje paralelo y montaje alterno. Estos dos elementos produjeron una revolución tremenda cuando fueron introducidos al cine traídos de la literatura al permitir darle mayor amplitud a las narrativas, así permitiendo recurrir a distintos tiempos y espacios enriqueciendo de esta manera, el tipo de historias que se podían contar, los videojuegos se han aprovechado de que el espectador/jugador actual ya conoce estos elementos gracias a los lenguajes antes mencionados, en especial el cinematográfico. Ahora estos dos elementos producen ese mismo cambio en los videojuegos, permitiendo realizar narrativas más complejas, que incluyen muchos más personajes principales y en el caso de los videojuegos, personajes que el jugador puede controlar como es el caso de los videojuegos analizados (Heavy Rain. 2010) y (GTA V. 2013). Además de permitir moverse entre un universo espacio-temporal mas interesante y complejo, en tanto al orden que es posible darles a los acontecimientos contados. La inclusión de estos elementos está generando y generará un montón infinito de posibilidades para el desarrollo tanto narrativo como audiovisual de los videojuegos. Esto lleva a la mención de que estos dos tipos de montaje se diferencian de su utilización cinematográfica en que el jugador es un cocreador, es decir, tiene la potestad de manejar esta herramienta a su antojo, en conclusión, es como un montajista en una sala de edición cinematográfica.

Como también se menciona en el análisis de los resultados la utilización del texto para exponer información es muy similar a lo que se hacía con los intertítulos en el periodo del cine silente, periodo al que pertenece la película con la que se realizó la comparación (Intolerancia. 1916). Esto lleva a pensar que los videojuegos se encuentran aún en una especie de "época muda" buscando herramientas para poder generar un lenguaje propio, y alejarse del cine, como lo hizo el cine de la literatura en su momento.

La utilización del texto es clave en los videojuegos actuales, sin embargo, ya comienzan a aparecer propuestas que evolucionan el lenguaje y prescinden de la utilización del texto para informar al jugador sobre su narrativa o su jugabilidad, como por ejemplo (Journey. 2012) y que apelan a ser más intuitivos. Siguiendo por esta línea, vale la pena preguntarse ¿hacia dónde se dirigen los videojuegos? Quizá sea posible que estos continúen en una evolución paralela a la que tuvo el cine y sea posible la aparición de propuestas alternativas, a las que valdrá la pena analizar en un futuro. De hecho, en el análisis realizado se puede ver que (Heavy Rain. 2010) carga un valor cinematográfico más puro que (GTA V. 2013), este último sigue siendo cercano al cine, sin embargo, los elementos cinematográficos comienzan a transformarse para abrir paso a un nuevo lenguaje, que, si bien proviene del cine, será distinto. Por eso es necesario seguir analizando a fondo los conceptos propuestos por Burch en 1970 que están llenos de otras convenciones utilizadas en el cine y que han marcado sus distintas líneas de evolución, en relación claramente con los videojuegos y como estos vayan evolucionando en años futuros, vale la pena también lanzar la pregunta de si ¿los videojuegos dejaran de 
ser un objeto meramente para el entretenimiento? $Y$ podrán convertirse en objetos que produzcan placer estético y reflexión social como ya lo son otros tipos de arte como la pintura, el cine, la fotografía, entre otros. Puede que analizando los videojuegos bajo los demás modos de representación propuestos por Burch sea posible encontrar descubrimientos todavía mas interesantes sobre los que se están desarrollando ahora mismo y los que se desarrollaran en un futuro en países con inquietudes tanto estéticas como sociales distintas a las inquietudes norteamericanas, como por ejemplo en Europa, Asia, África o Latinoamérica.

\section{Notas finales}

${ }^{1}$ Wagner se refería a un arte que integrara para la época las seis artes existentes: la música, la danza, la poesía, la pintura, la escultura y la arquitectura.

${ }^{2}$ Termino en ingles que puede traducirse al español como continuidad.

${ }^{3}$ En el cine clásico, por ejemplo, se utilizaban estos efectos para representar estados oníricos en un personaje o también cuando un personaje se encontraba bajo el efecto de alguna sustancia que modificará su percepción de la realidad.

${ }^{4}$ Termino en ingles que podría definirse como el momento en el que el jugador puede controlar las acciones del juego.

${ }^{5}$ Termino en ingles que se traduce al español como cinemática.

\section{Referencias}

Bordwell, David y Thompson, Kristin. 1995. El arte cinematográfico. Traducido del inglés por Yolanda Fontal Rueda. Paidós iberica.

Brown, Harry. 2008. Videogames and education, Taylor and Francis Ltd.

Burch, Noel. 1985. Praxis del cine. Traducido del inglés por Ramón Font. Editorial fundamentos.

Burch, Noel. 1987. El tragaluz del infinito: contribución a la genealogía del lenguaje cinematográfico. Catedra.

Cage, David. 2010. Heavy Rain (Versión computadora). Quantic Dream.

Chen, Jenova. 2012. Journey (Play station 4). Thatgamecompany.

Cuadrado, Alfonso. 2013. "Acciones y emoción: un estudio de la jugabilidad en Heavy Rain" En HOMO VIDEOLUDENS 2.0 De Pacman a la gamification 2013. Organizado por Scolari, Carlos A. Laboratori de Mitjans Interactius. Universitat de Barcelona.

Einsenstein, Sergei. 1949. The film form, Harcourt brace javanovich, inc.

Etxeberria, Félix. 2001. Videojuegos y educación. REVISTA ELECTRÓNICA - Teoría de la Educación: Educación y Cultura en la Sociedad de la Información. https://gredos.usal.es/bitstream/handle/10366/56438/ TEE 2001 _V2_videojuegoseducacion pdf. pdf? sequence=1\&isAllowed=y

Griffiths, Mark. 2002. "The educational benefits of videogames" en Education and healt $n^{\circ} 3$ : 47-51.

Gubern, Roman. 2016. Historia del cine, Anagrama.

Gosciola, Vicente. 2009. "Narrativa audiovisual de los video juegos: Aspectos comunes con el cine" en Cuadernos de información $n^{\circ} 25$ : 51-60.

Henry, Jenkins. 2009. Fans, blogueros y videojuegos. Traducido del inglés por Pablo Hermida Lazcano. Paidós.

Hidalgo Vázquez, Ximena Paula. 2011. Videojuegos un arte para la historia del arte. Tesis doctoral, Universidad de Granada.

Houser, Dan. 2013. Grand Theft Auto V (Versión computadora). Rockstar North.

Intolerancia. 1916. Por David Wark Griffth. Estados Unidos: Triangle \& Warkl. Digital.

Jiménez Mateo, Carmen. 2018.El ajuste en los videojuegos: análisis de las escenas cinemáticas de Harry Potter y las Reliquias de la Muerte. Tesis de pregrado, Universitat Jaume I.

Juul, Jasper. 2011.Half-Real: Video Games between Real Rules and Fictional Worlds, The MIT Press.

Marzal, Javier. 2015."La larga sombra del padre Huellas de Intolerancia de David Wark Griffith en la historia del cine" en Eu-topias n¹0: 95-105.

Pedro Herrero. La industria del videojuego facturó en 2020, en todo el mundo, más que el cine y los deportes juntos en EEUU:Meristation. https://as.com/ meristation/2020/12/26/noticias/1608992024_963325. html. Consultado el 2 de abril de 2021.

Peña J, Hancock JT.2006. "An Analysis of Socioemotional and Task Communication in Online Multiplayer Video Games" en Communication Research n³3:92-109.

Planells, Antón. 2011. "Usos sociales y analogías estéticas: el cine primitivo y el nacimiento de los videojuegos" en Telos: Cuadernos de comunicación e innovación n88: 46-57.

Prieto, Rafael. Medina, Nuria y López, Josefa. 2016. "Interacción en videojuegos serios". Comunicación presentada en la Universidad de Salamanca, septiembre.

Pázhitnov, Alekséi. 1984. Tetris (Arcade). The Tetris Company.

Pérez Latorre, Óliver. 2010.Análisis de la significación del videojuego Fundamentos teóricos del juego, el mundo narrativo y la enunciación interactiva como perspectivas de estudio del discurso. Tesis doctoral, Universitat Pompeu Fabra.

Salas Sabal, Israel. 2016.La narrativa cinematográfica en los videojuegos. Tesis de pregrado,Universitat Oberta de Catalunya.

Sánchez, Rafael. 1970. Montaje cinematográfico arte de movimiento, Pomaire.

Santoyo Venegas, Rita. 2013. "Narración, Estética y Política: La imagen en el arte y el diseño". Comunicación presentada en la Universidad Nacional Autónoma de México, octubre.

Tarkovski, Andrei. Esculpir el tiempo. Reflexiones sobre el arte, la estética y la poética del cine. Traducido del alemán por Enrique Banus Irusta, Ediciones Rialp S.A.

Tavinor, Grant. 2009. The Art of Videogames, John Wiley y Sons.

Videlba Fariñas, M. 2016. VIDEOJUEGOS Y CINE. APROXIMACIONES $Y$ PERSPECTIVAS DESDE LA NARRATOLOGÍA CINEMATOGRÁFICA PARA EL ANÁLISIS DEL VIDEOJUEGO. Tesis de pregrado, Universidad de los Andes.

Villani Daniela, Carissola Claudia, Triberti Stefano, Marchetti Antonella, Gilli Gabriella, Riva Giussepe. 2018. "Videogames for Emotion Regulation: A Systematic Review" en Games for health journal n²: 85-99.

Wagner, Richard. 1849. La obra de arte del futuro. Traducido del alemán por Joan B. Llinares y Francisco López. Publicacions de la Universitat de Valéncia.

Wolf, Mark J. y Perron, Bernard. 2005. "Introducción a la teoría del videojuego" en Revista de comunicació audiovisual $n^{\circ} 4$ 